\title{
Forest summer albedo is sensitive to species and thinning: how should we account for this in Earth system models?
}

\author{
J. Otto ${ }^{1}$, D. Berveiller ${ }^{2}$, F.-M. Bréon ${ }^{1}$, N. Delpierre ${ }^{2}$, G. Geppert ${ }^{3}$, A. Granier ${ }^{4}$, W. Jans ${ }^{5}$, A. Knohl ${ }^{6}$, A. Kuusk ${ }^{7}$, \\ B. Longdoz ${ }^{4}$, E. Moors ${ }^{5}$, M. Mund ${ }^{6}$, B. Pinty ${ }^{8}$, M.-J. Schelhaas ${ }^{5}$, and S. Luyssaert ${ }^{1}$ \\ ${ }^{1}$ LSCE, CEA-CNRS-UVSQ, Gif-sur-Yvette, France \\ ${ }^{2}$ CNRS-Université Paris-Sud-AgroParisTech, Unité ESE, Orsay, France \\ ${ }^{3}$ Max Planck Institute for Meteorology, Hamburg, Germany \\ ${ }^{4}$ Institut Nationale de la Recherche Agronomique, Unité Ecophysiologie Forestières, Champenoux, France \\ ${ }^{5}$ Alterra, Wageningen University and Research Centre, Wageningen, the Netherlands \\ ${ }^{6}$ Georg August University of Göttingen, Göttingen, Germany \\ ${ }^{7}$ Tartu Observatory, Tõravere, Estonia \\ ${ }^{8}$ European Commission, DG Joint Research Centre, Institute for Environment and Sustainability, \\ Climate Risk Management Unit, Ispra, Italy
}

Correspondence to: J. Otto (juliane.otto@lsce.ipsl.fr)

Received: 15 July 2013 - Published in Biogeosciences Discuss.: 25 September 2013

Revised: 4 March 2014 - Accepted: 5 March 2014 - Published: 29 April 2014

\begin{abstract}
Although forest management is one of the instruments proposed to mitigate climate change, the relationship between forest management and canopy albedo has been ignored so far by climate models. Here we develop an approach that could be implemented in Earth system models. A stand-level forest gap model is combined with a canopy radiation transfer model and satellite-derived model parameters to quantify the effects of forest thinning on summertime canopy albedo. This approach reveals which parameter has the largest affect on summer canopy albedo: we examined the effects of three forest species (pine, beech, oak) and four thinning strategies with a constant forest floor albedo (light to intense thinning regimes) and five different solar zenith angles at five different sites $\left(40^{\circ} \mathrm{N} 9^{\circ} \mathrm{E}-60^{\circ} \mathrm{N} 9^{\circ} \mathrm{E}\right)$.

During stand establishment, summertime canopy albedo is driven by tree species. In the later stages of stand development, the effect of tree species on summertime canopy albedo decreases in favour of an increasing influence of forest thinning. These trends continue until the end of the rotation, where thinning explains up to $50 \%$ of the variance in near-infrared albedo and up to $70 \%$ of the variance in visible canopy albedo.

The absolute summertime canopy albedo of all species ranges from 0.03 to 0.06 (visible) and 0.20 to 0.28 (near-
\end{abstract}

infrared); thus the albedo needs to be parameterised at species level. In addition, Earth system models need to account for forest management in such a way that structural changes in the canopy are described by changes in leaf area index and crown volume (maximum change of 0.02 visible and 0.05 near-infrared albedo) and that the expression of albedo depends on the solar zenith angle (maximum change of 0.02 visible and 0.05 near-infrared albedo). Earth system models taking into account these parameters would not only be able to examine the spatial effects of forest management but also the total effects of forest management on climate.

\section{Introduction}

Albedo is the fraction of solar energy reflected from a surface back to the atmosphere; it is controlled by the characteristics of the surface, cloudiness and the position of the sun. The size of the land surface albedo is a major factor controlling the energy budget of the Earth and albedo is thus a key parameter in the Earth's climate system. Of the main vegetated land surface types, i.e. trees, grasses and crops, trees generally have the lowest albedo, trapping more solar radiation than shorter vegetation (Amiro et al., 2006; Betts and Ball, 
1997; Pielke and Avissar, 1990; Robinson and Kukla, 1984). The differences in albedo between broad vegetation classes, i.e. evergreen and deciduous forest, and among other vegetation types are reasonably well established, as are the climate effects that follow a change in albedo (Anderson et al., 2011; Bala et al., 2007; Bathiany et al., 2010; Betts, 2000; Pielke et al., 1998; Schwaiger and Bird, 2010).

Finer-scale albedo effects, such as those of species diversity in the canopy, tree species and forest management, remain poorly documented. Although a body of literature linking forest albedo to forest thinning is emerging, process understanding is still fragmented, because these studies are limited to individual stands or single species and the observed stand-level relationships have not been explored on a regional or global scale. The site-level effect of forest thinning on albedo has been quantified for a handful of stands. For a pine forest in Arizona thinning resulted in a small increase in albedo (Dore et al., 2012). In contrast, a mid-rotation stand of loblolly pine in North Carolina showed lower average albedo compared to a recently established stand on a clear-cut site (Sun et al., 2010). The same effect was observed for a thinned pine forest in New Zealand (Kirschbaum et al., 2011). The first thinning of a managed Norway spruce stand in Finland was simulated to reduce the albedo by $10 \%$, whereas the subsequent thinning events had a smaller influence on stand albedo (Rautiainen et al., 2011). This reduction in surface albedo was reported to be a function of canopy structure and thinning (Rautiainen et al., 2011).

Maximising forests' sequestration of atmospheric carbon dioxide through forest management, including species selection and stand thinning, is one of the key instruments proposed to mitigate climate change (UN, 1998). However, managing forests for carbon sequestration will at the same time affect the biophysical interaction with the atmosphere through changes in albedo, canopy roughness and evapotranspiration. Thus, before we can hope to mitigate climate change through forest management we must quantify and understand the full range of climate impacts through both biogeochemical and biophysical land-atmosphere interactions that forest management can control. Land surface models, including forest growth and management (Bellassen et al., 2010), are an ideal tool for analysing this effect on a larger scale. The radiation transfer schemes in today's models, however, are not suitable for simulating the effect of changes in canopy structure on albedo (Loew et al., 2013). Here, we present an approach that could be implemented in Earth system models to fill this gap in our knowledge.

We couple a tree-based forest gap model to a canopy radiation transfer model and use satellite-derived model parameters to determine which factor has the strongest effect on summertime canopy albedo: (1) site location and thereby different solar zenith angles, (2) tree species or (3) thinning strategies.

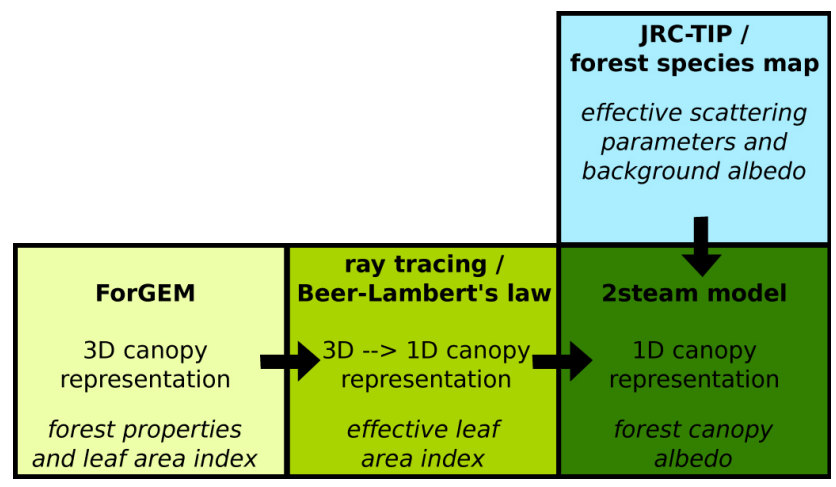

Fig. 1. Sketch of the model chain linking the forest gap-model, ray tracing, two-stream radiation transfer model and remote-sensingbased model parameters. Model output is given at the bottom of each box and the dimensions of the canopy representation are indicated by 3-D and 1-D for a three-dimensional and one-dimensional representation of the forest canopy, respectively. The variables calculated by the single models are in italics. ForGEM: Forest Genetics, Ecology and Management; JRC-TIP: Joint Research Centre Two-stream Inversion Package.

\section{Materials and methods}

\subsection{The modelling chain}

The effects of forest thinning on stand structure were quantified using a tree-based forest gap model called ForGEM (FORest Genetics, Ecology and Management; Kramer et al., 2008). Radiation absorption, scattering and transmission by the forest canopy were then calculated from a radiation transfer model (Pinty et al., 2006) using satellite-derived, speciesspecific and effective vegetation radiative properties (Fig. 1).

\subsection{Forest gap model (ForGEM)}

The forest gap model ForGEM is a spatially explicit, individual tree model that quantifies ecological interactions and forest management. Previously, ForGEM has been applied to diverse research questions ranging from the effects of wind throw on carbon sequestration to the adaptive potential of tree species under changing climate (Kramer et al., 2008; Schelhaas, 2008; Schelhaas et al., 2007). Intermodel comparison (Fontes et al., 2010) demonstrated that ForGEM is one of the few processed-based models that are capable of simulating complex relationships and interactions between tree species and forest management strategy. Direct validation of the simulated canopy structure against observations has not yet been achieved due to the absence of sufficiently large observational data sets. This is, however, likely to change in the near future owing to the rapid development of radar-based technology (Raumonen et al., 2013). In the mean time, inter-model comparison (Fontes et al., 2010) and stand level validation (Kramer et al., 2008) increased our confidence that the model simulates a realistic 
canopy structure under different management strategies. In this study, ForGEM was set up to simulate forest stands composed of different species and subject to different thinning regimes over one rotation (Table 1). These simulations provided us with key variables to describe the forest canopy structure, i.e. tree height, crown volume as cylinders, leaf mass, leaf area index (LAI) and the spatial position of all trees within the stand.

\subsection{Canopy radiation transfer scheme}

The complexity of radiation transfer makes it difficult to accurately simulate radiation transfer through structurally and optically complex vegetation canopies without using explicit 3 -D models. Nevertheless, the 1-D canopy radiation transfer model by Pinty et al. (2006) has been shown to accurately simulate both the amplitude and the angular variations of all radiant fluxes with respect to the solar zenith angle (Widlowski et al., 2011). However, this requires the use of adapted variables: we refer to these as "effective" variables, which replace true state variables (Pinty et al., 2004). For example, the value of LAI used in the 1-D model (see Table 1) is calculated from the true LAI such that the 1-D model reproduces the radiative fluxes of the 3-D model. LAI in the 3-D model is the true state variable; LAI in the 1-D model is the effective LAI. The effective LAI thus expresses the amount of vegetation that a 1-D model requires to match the solar radiation attenuated by a 3-D model. Any change in the true LAI is reflected in the representation of effective LAI including information on changes in canopy structure.

The effective LAI was calculated by means of a "raytracing approach". For an incident single ray, the approach tests whether that ray encounters a tree and measures the distance it travels from the first contact with a canopy element before reaching the forest floor. This process was repeated 100000 times for different locations over the stand to estimate the probability density function of the distance rays travelling within the canopy. For a given solar angle, the probability density function was combined with the crown density (LAI per crown volume; Bréda, 2003) to calculate the fraction of light reaching the forest floor without meeting a canopy element (Pinty et al., 2011a, 2011b). This fraction was then used as input for the inverted Beer-Lambert's law (see Eq. (25) in Pinty et al., 2004) to derive the effective LAI. This approach requires the explicit position of trees and their crown dimensions; these were retrieved from the ForGEM simulations mentioned above.

\subsection{Parameters for the radiation transfer scheme}

The following vegetation radiative properties are required to calculate the albedo from the effective LAI: the effective leaf single scattering albedo (for both visible (VIS) and nearinfrared (NIR) wavelengths), the effective preferred scattering direction of vegetation scattering (VIS and NIR), and the so-called true background albedo which is the albedo of the surface below the dominant tree canopy (VIS and NIR). All parameters were taken from the Joint Research Centre Twostream Inversion Package (JRC-TIP) (Pinty et al., 2011a, 2011b), software which inverts the two-stream model (Pinty et al., 2006) to best fit the Moderate Resolution Imaging Spectroradiometer (MODIS, Schaaf et al., 2002) broadband visible and near-infrared white-sky surface albedo from 2001 to 2010 at 0.01 degree resolution. The parameters derived are equally suitable for calculating white-sky albedo and blacksky albedo.

Parameter values were only selected from the JRC-TIP if the posterior standard deviation of the probability density function was significantly smaller than the prior standard deviation, because this condition ensures statistically significant values. The vast majority of the retrieved values remained close to their prior values. The radiative properties extracted from JRC-TIP were successfully compared with in situ measurements for deciduous and needleleaf forest sites (Pinty et al., 2008, 2011c). It should be noted, however, that without field observations to constrain the prior values of the canopy and background properties used in the inversion, the right fluxes may be obtained from a combination of the wrong canopy and background properties, especially for sparse canopies.

Effective species-specific radiative properties were derived from JRC-TIP by masking the scattering parameters with a forest species map for Europe (Brus et al., 2011). This map gives a spatial distribution of the 20 dominant tree species or species groups over Europe at $1 \times 1 \mathrm{~km}$ resolution. As this study considers only pure forest stands, to avoid signal contamination only pixels where a single species dominates (Brus et al., 2011) were selected. The effective scattering and true background values for pine (Pinus sylvestris L.), beech (Fagus sylvatica L.) and oak (Quercus robur L. or $Q$. petraea Liebl) are listed in Table 2.

The diversity of techniques to measure and model albedo has resulted in two different albedo specifications. In this study, albedo is defined as the black-sky albedo, also referred to as directional-hemispherical reflectance (DHR). This means that the surface is illuminated with a collimated beam of light from a single direction and the scattering is the integral over all viewing directions (Martonchik et al., 2000). It is not normally measured in the field where most measurements will also include illumination from diffuse solar radiation. This so-called white-sky albedo is used for validation, assuming that isotropic incoming radiation prevails during European summer. We report the albedo for direct-beam light and for the visible $(0.3-0.7 \mu \mathrm{m})$ and near-infrared $(0.7-$ $3.0 \mu \mathrm{m}$ ) bands of the spectrum separately. The term 'canopy albedo' describes the albedo of a combined shortwave band $(0.3-3.0 \mu \mathrm{m})$ at the top of the canopy of a forest stand. If we refer to another albedo quantity or spectral band, it is mentioned in the text. 
Table 1. Mean effective LAI over one rotation for the different thinning strategies, tree species and locations. P: Pinus sylvestris L.; F: Fagus sylvatica L.; and Q: Quercus robur L. or Q. petraea Liebl.(I) unmanaged forest: the forest stand is an even-aged forest and no management measures are applied. (II) light thinning: the forest stand is thinned from below according to yield tables. The trees with the smallest diameters are removed until the required density from the yield table is reached. This is repeated every 5 years. (III) strong thinning: this measure is similar to (II) but only half the density of the yield tables is applied, i.e. more trees are removed than in the simulations (II). (IV) intense thinning: this measure is similar to (III) but the thinning occurs only every 10 years, to the same density as (III) for the same age.

\begin{tabular}{l|ccc|ccc|cc|cc|cc|c}
\hline location/ type/ species & \multicolumn{3}{|c|}{ unmanaged forest (I) } & \multicolumn{2}{|c|}{ light thinning (II) } & \multicolumn{2}{|c|}{ strong thinning (III) } & \multicolumn{2}{|c}{ intense thinning (IV) } \\
\hline & $\mathrm{P}$ & $\mathrm{F}$ & $\mathrm{Q}$ & $\mathrm{P}$ & $\mathrm{F}$ & $\mathrm{Q}$ & $\mathrm{P}$ & $\mathrm{F}$ & $\mathrm{Q}$ & $\mathrm{P}$ & $\mathrm{F}$ & $\mathrm{Q}$ \\
\hline $60^{\circ} \mathrm{N} 9^{\circ} \mathrm{E}$ & 2.55 & 4.45 & 3.12 & 1.93 & 2.97 & 2.54 & 1.14 & 1.72 & 1.55 & 1.22 & 1.80 & 1.62 \\
$55^{\circ} \mathrm{N} 9^{\circ} \mathrm{E}$ & 2.51 & 4.35 & 3.06 & 1.89 & 2.87 & 2.48 & 1.12 & 1.65 & 1.50 & 1.19 & 1.72 & 1.58 \\
$50^{\circ} \mathrm{N} 9^{\circ} \mathrm{E}$ & 2.46 & 4.22 & 2.98 & 1.84 & 2.75 & 2.41 & 1.09 & 1.57 & 1.45 & 1.16 & 1.64 & 1.53 \\
$45^{\circ} \mathrm{N} 9^{\circ} \mathrm{E}$ & 2.40 & 4.06 & 2.89 & 1.79 & 2.61 & 2.33 & 1.05 & 1.48 & 1.40 & 1.12 & 1.55 & 1.47 \\
$40^{\circ} \mathrm{N} 9^{\circ} \mathrm{E}$ & 2.34 & 3.85 & 2.77 & 1.73 & 2.45 & 2.24 & 1.02 & 1.40 & 1.34 & 1.09 & 1.46 & 1.41 \\
\hline
\end{tabular}

Table 2. Observed mean radiative properties for the tree species used in this study for June: effective single scattering albedo, effective preferred direction of scattering and true background albedo were extracted from the JRC-TIP product. One standard deviation is given in brackets. In addition, the same variables are given for each site used for the validation of the model chain. Legend for single sites: Loobos in the Netherlands (coded NL-Loo, $52.17^{\circ} \mathrm{N}, 5.74^{\circ} \mathrm{E}$ ), Järvselja in Estonia (coded EE-Jär, 58.31 ${ }^{\circ} \mathrm{N}, 27.30^{\circ} \mathrm{E}$ ), Hainich in Germany (coded DE-Hai, $51.08^{\circ} \mathrm{N}, 10.45^{\circ} \mathrm{E}$ ), Hesse in France (coded FR-Hes, $48.67^{\circ} \mathrm{N}, 7^{\circ} .7^{\circ} \mathrm{E}$ ), Fontainebleau in France (coded FR-Fon, $48.48^{\circ} \mathrm{N}$, $\left.\mathrm{E} 2.78^{\circ} \mathrm{E}\right)$.

\begin{tabular}{|c|c|c|c|c|c|c|}
\hline & $\begin{array}{l}\text { effective } \\
\text { single } \\
\text { scattering } \\
\text { albedo } \\
\text { (VIS) }\end{array}$ & $\begin{array}{l}\text { effective } \\
\text { direction of } \\
\text { scattering } \\
\text { (VIS) }\end{array}$ & $\begin{array}{l}\text { effective } \\
\text { single } \\
\text { albedo } \\
\text { scattering } \\
\text { (NIR) }\end{array}$ & $\begin{array}{l}\text { effective } \\
\text { direction of } \\
\text { scattering } \\
\text { (NIR) }\end{array}$ & $\begin{array}{l}\text { true } \\
\text { background } \\
\text { albedo } \\
\text { (VIS) }\end{array}$ & $\begin{array}{l}\text { true } \\
\text { background } \\
\text { albedo } \\
\text { (NIR) }\end{array}$ \\
\hline Pinus sylvestris & $0.15(0.03)$ & $0.99(0.02)$ & $0.73(0.04)$ & $2.01(0.05)$ & $0.09(0.04)$ & $0.17(0.08)$ \\
\hline at NL-Loo & 0.12 & 0.97 & 0.67 & 1.95 & 0.06 & 0.10 \\
\hline at EE-Jär & 0.12 & 0.96 & 0.67 & 1.93 & 0.08 & 0.14 \\
\hline Fagus spp & $0.15(0.03)$ & $0.99(0.03)$ & $0.74(0.04)$ & $2.05(0.07)$ & $0.13(0.04)$ & $0.25(0.09)$ \\
\hline at DE-Hai & 0.13 & 0.97 & 0.74 & 2.07 & 0.16 & 0.29 \\
\hline at FR-Hes & 0.17 & 1.01 & 0.76 & 2.10 & 0.15 & 0.30 \\
\hline Quercus robur \& $Q$. petraea & $0.18(0.02)$ & $1.02(0.02)$ & $0.76(0.03)$ & $2.09(0.04)$ & $0.15(0.02)$ & $0.28(0.05)$ \\
\hline at FR-Fon & 0.17 & 1.01 & 0.75 & 2.08 & 0.15 & 0.29 \\
\hline
\end{tabular}

\subsection{The species-thinning experiment}

The above model chain was applied to pine, beech and oak single-species forests. For each species we simulated four different thinning strategies, going from unmanaged to intensively thinned forest (see Table 1). All simulations were based on the growing conditions that approximate to the highest site class of Dutch yield tables (Jansen et al., 1996), using observed climate over the period 19752010 for the central Netherlands from the Monitoring Agricultural Resources (MARS) database (accessed online 21 January 2014: www.marsop.info/marsop3/). The simulations start with about 5000 trees per hectare, aged between 10 and 15 years and forest regeneration was considered absent within a rotation. All simulations were performed for 1 ha of forest. For each species and thinning type, canopy albedo was calculated for a transect across Europe along the $9^{\circ} \mathrm{E}$ line of longitude stretching from $40^{\circ}$ to $60^{\circ} \mathrm{N}$ in discrete steps of $5^{\circ}$. The selected spatial domain is an ecologically feasible growing area for the species under study. Canopy albedo was reported for the location-specific solar-noon zenith angle of the sun at summer solstice.

\subsection{Validation}

The radiation transfer scheme was validated against observational data of forest properties from the five forest sites under study (two pine, two beech, one oak forest; see Table 3 and Appendix). We compared the observed top-of-thecanopy albedo data and mean MODIS-collection-5 albedo for June 2001 to 2010 to the modelled white-sky canopy albedo values for each site. For the validation, the radiation transfer model was forced by observed diameter and height distribution and single-sided LAI and, in the case of needles, hemispherical LAI. In contrast to the model chain used in the remainder of the study, the validation thus did not make use of ForGEM simulations to describe the canopy structure in the radiation transfer model. 
Table 3. Data availability for site level validation. The symbol $(*)$ indicates that for FR-Hes tree height was calculated from provided site-specific allometric relationship.

\begin{tabular}{llllllllll}
\hline Site & $\begin{array}{l}\text { 2-way } \\
\text { pyrano- } \\
\text { meters }\end{array}$ & $\begin{array}{l}\text { CHRIS/UAV } \\
\text { spectro- } \\
\text { meter }\end{array}$ & $\begin{array}{l}\text { Gap } \\
\text { fraction }\end{array}$ & $\begin{array}{l}\text { Tree } \\
\text { position }\end{array}$ & DBH & $\begin{array}{l}\text { Tree } \\
\text { height }\end{array}$ & $\begin{array}{l}\text { Crown } \\
\text { radius }\end{array}$ & $\begin{array}{l}\text { Crown } \\
\text { length }\end{array}$ & LAI \\
\hline DE-Hai & $\mathrm{y}$ & $\mathrm{n}$ & $\mathrm{n}$ & $\mathrm{y}$ & $\mathrm{y}$ & $\mathrm{y}$ & $\mathrm{y}$ & $\mathrm{y}$ & $\mathrm{y}$ \\
FR-Hes & $\mathrm{y}$ & $\mathrm{n}$ & $\mathrm{n}$ & $\mathrm{n}$ & $\mathrm{y}$ & $\mathrm{y}$ & $\mathrm{n}$ & $\mathrm{n}$ & $\mathrm{y}$ \\
EE-Jar & $\mathrm{n}$ & $\mathrm{y}$ & $\mathrm{y}$ & $\mathrm{y}$ & $\mathrm{y}$ & $\mathrm{y}$ & $\mathrm{y}$ & $\mathrm{y}$ & $\mathrm{y}$ \\
FR-Fon & $\mathrm{y}$ & $\mathrm{n}$ & $\mathrm{n}$ & $\mathrm{y}$ & $\mathrm{y}$ & $\mathrm{y}$ & $\mathrm{n}$ & $\mathrm{n}$ & $\mathrm{y}$ \\
NL-Loo & $\mathrm{y}$ & $\mathrm{n}$ & $\mathrm{n}$ & $\mathrm{y}$ & $\mathrm{y}$ & $\mathrm{y}$ & $\mathrm{n}$ & $\mathrm{n}$ & $\mathrm{y}$ \\
\hline
\end{tabular}

Foliage in tree crowns often forms clumps, and typically clumping is more important in needleleaf compared to broadleaf plants. The so-called needle-to-shoot level clumping used in this study was quantified using the needle-toshoot area ratio, which is measured through shoot samples and varies from species to species (Chen, 1996). The needleto-shoot clumping factor for pine forests, taken from observations by Chen (1996) is 1.55 (average of values given in Chen's table 4). The observed hemispherical leaf area index (LAI of conifers) divided by the needle-to-shoot area ratio (1.55) then equals the LAI.

\subsection{Statistical analysis}

Multi-way analysis of variance (ANOVA) was used to quantify the relative contributions of species, latitude and thinning and species-latitude, species-thinning and latitude-thinning interactions to summertime canopy albedo. In the analysis all factors were considered to be so-called random effects. The analysis was repeated for every model year for the visible, near-infrared and shortwave wavelength bands separately to derive the temporal variability during rotation in the driving factors (species, latitude and thinning). All factors were tested but for the sake of clarity only factors that explained more than $10 \%$ of the variance are shown.

\subsection{Radiative forcing}

We applied a simplified concept of radiative forcing to quantify the site-specific per-unit area climate impacts of forest thinning on summertime canopy albedo. The radiative forcing is the mean change in reflected shortwave radiation in June at the top of the atmosphere, resulting from changes in surface albedo due to forest thinning and species selection. Following the calculations presented by Bright et al. (2012) and Cherubini et al. (2012) we compared the summertime canopy albedo changes between the intensively managed and the unmanaged forest stands for each year. The radiative forcing $(R F)$ was calculated as

$\mathrm{RF}=-R_{\mathrm{TOA}} f \Delta \alpha$ where $R_{\mathrm{TOA}}$ is the incoming solar radiation flux at the top of the atmosphere, $f$ is a two-way atmospheric transmittance parameter accounting for reflection and absorption of solar radiation through the atmosphere, and $\Delta \alpha$ is the difference in surface albedo between unmanaged and managed forest.

The two-way atmospheric transmittance, $f$, is estimated as the product between the clearness index, $K$, which is the fraction of downwelling solar radiation at the top of the atmosphere that reaches the Earth's surface, and the atmospheric transmittance factor, $T$, which is the fraction of radiation reflected at the surface arriving back at the top of the atmosphere. The clearness index, $K$, was derived for every site specifically from NASA's Solar Surface Energy project (accessed online 22 January 2014 at: https://eosweb.larc.nasa. gov/cgi-bin/sse/sse.cgi). For the atmospheric transmittance factor, $T$, we use a global annual average of 0.854 (Lenton and Vaughan, 2009), whose suitability was tested by Cherubini et al. (2012). The incoming solar radiation, $R_{\mathrm{TOA}}$, on any given day of the year (from 1 to 365 ) can be calculated from latitude, the declination angle and the sunset-hour angle, following equations reported by Bright et al. (2012). Eq.(1) is applied for the month June and for the latitudinal transect from $40^{\circ}-60^{\circ} \mathrm{N}$ at $9^{\circ} \mathrm{E}$.

\section{Results}

\subsection{Validation of the model chain}

The simulated summertime white-sky canopy albedo of deciduous forest lies within the range of the MODIS-observed albedo values (Fig. 2). Given that MODIS albedo was used to derive the parameters of the radiation transfer model, this comparison only validates the effective LAI simulated by ForGEM and the ray-tracing approach. Furthermore, the radiative transfer model captures the general trend of lower albedo in needleleaf compared to broadleaf deciduous forest (Fig. 2). However, we overestimated the shortwave albedo of pine forest in comparison to site measurements (NL-Loo by 0.048 shortwave, EE-Jär 0.058 near-infrared), see Appendix for further details of the sites. The partitioning into visible and near-infrared (EE-Jär) suggests that the overestimation 


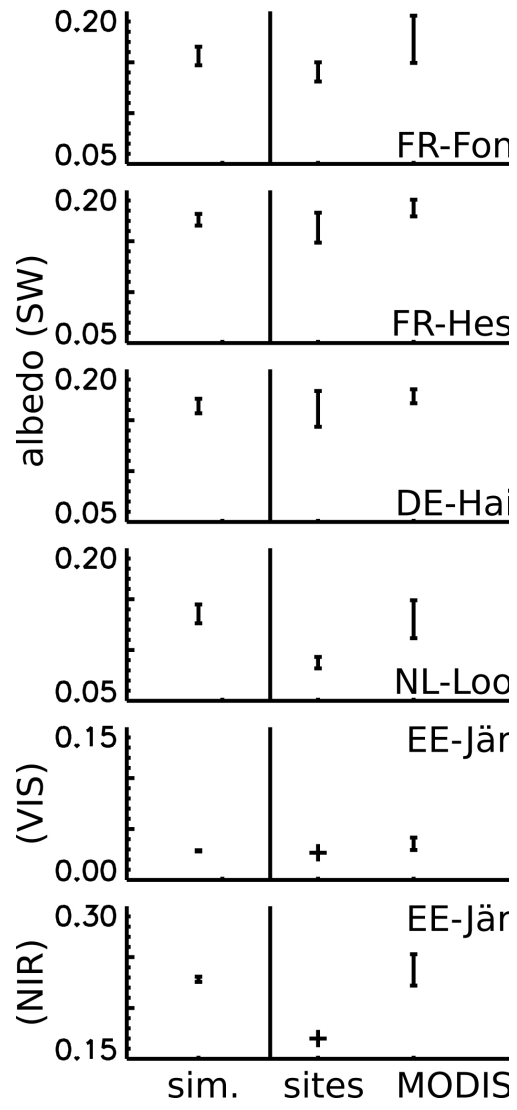

Fig. 2. Comparison of simulated June albedo for five different sites (left column) to in situ and satellite observations. The range of simulated albedo is shown for different crown allometry used to estimate crown volume from observed tree diameters. The range of in situ observations is taken from the $2 \mathrm{~h}$ window centred on local solar noon in June at each site during the years 1999 and 2010. EE-Jär is a single measurement (6 March 2013) but separated into visible and near-infrared albedo. The range of MODIS (2001-2010) observations are derived from nine pixels surrounding the tower. DE-Hai: beech; FR-Hes: beech; FR-Fon: oak; EE-Jär: pine; NL-Loo: pine.

Table 4. Maximum range of changes in summertime canopy albedo between managed and unmanaged forest over one rotation driven by thinning strategies, across all species and solar zenith angles; by species, across all thinning strategies and solar zenith angels; and by solar zenith angle, across all thinning strategies and species. For more explanation, see Table 1.

\begin{tabular}{lcc}
\hline maximum range & visible albedo & near-infrared albedo \\
\hline thinning strategies & 0.02 & 0.06 \\
species & 0.03 & 0.07 \\
solar zenith angle & 0.02 & 0.05 \\
\hline
\end{tabular}

occurs in the near-infrared wavelength band compared to the single-site measurement.

The gap fraction at EE-Jär was measured in 2007 and 2008 and our simulations resulted in a slightly smoother decline

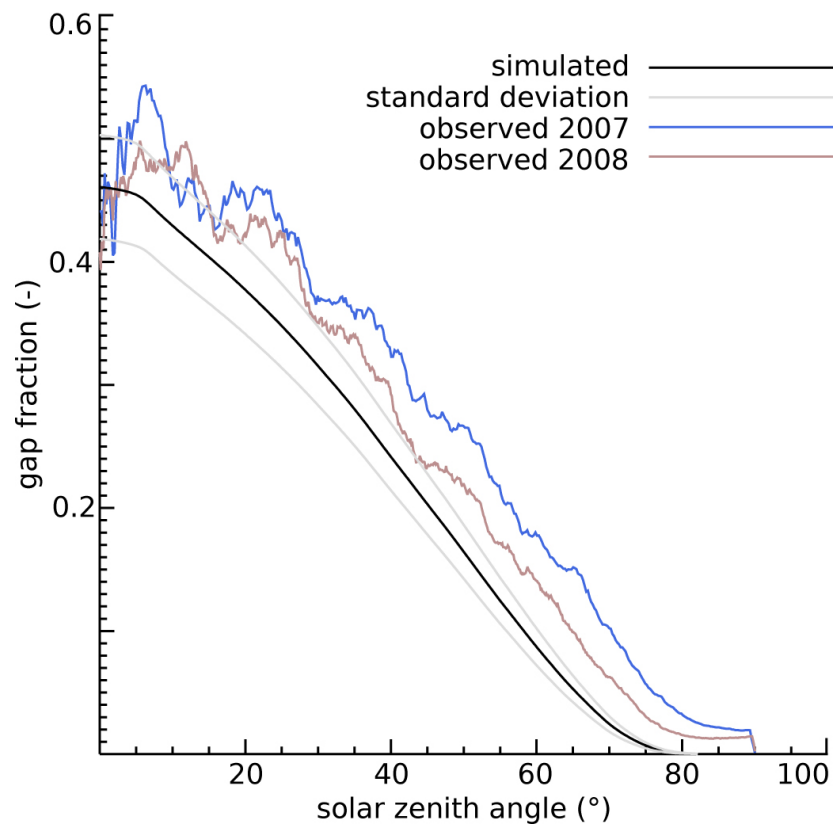

Fig. 3. Gap fraction measured in 2007 and 2008 at the EE-Jär pine forest compared to the modelled gap fraction.

compared to the observations (Fig. 3). We tested how this observed or simulated bias in canopy cover translates into an albedo bias by comparing model runs forced by either the modelled or the observed gap fraction. The slight underestimation of the simulated gap fraction propagates through the multi-scattering processes, especially in the near-infrared domain; this leads to the shortwave summertime albedo being overestimated in the pine forest. However, the underestimation of the gap fraction explains no more than 0.003 of the difference in near-infrared albedo.

\subsection{Attribution}

The maximum change in black-sky albedo over one rotation between managed and unmanaged forest is of the same order of magnitude (Table 4) for the three factors, namely species, thinning strategies and different latitudes (i.e. solar zenith angle). The maximum range reaches 0.03 in the visible and 0.07 in the near-infrared domain.

A multi-way ANOVA was performed for three different species, four thinning strategies and five different latitudes (see Table 1). Different factors contribute to the variance of summertime canopy black-sky albedo in the visible, nearinfrared and shortwave wavelength bands (Fig. 4). During stand establishment, summertime canopy albedo is driven by tree species. In the following stages of stand development, the effect of tree species on summertime canopy albedo decreases in favour of an increasing influence of forest thinning. These trends continue until the end of the rotation, where thinning explains up to $50 \%$ of the variance in near-infrared summertime albedo and up to $70 \%$ of the variance in visible 

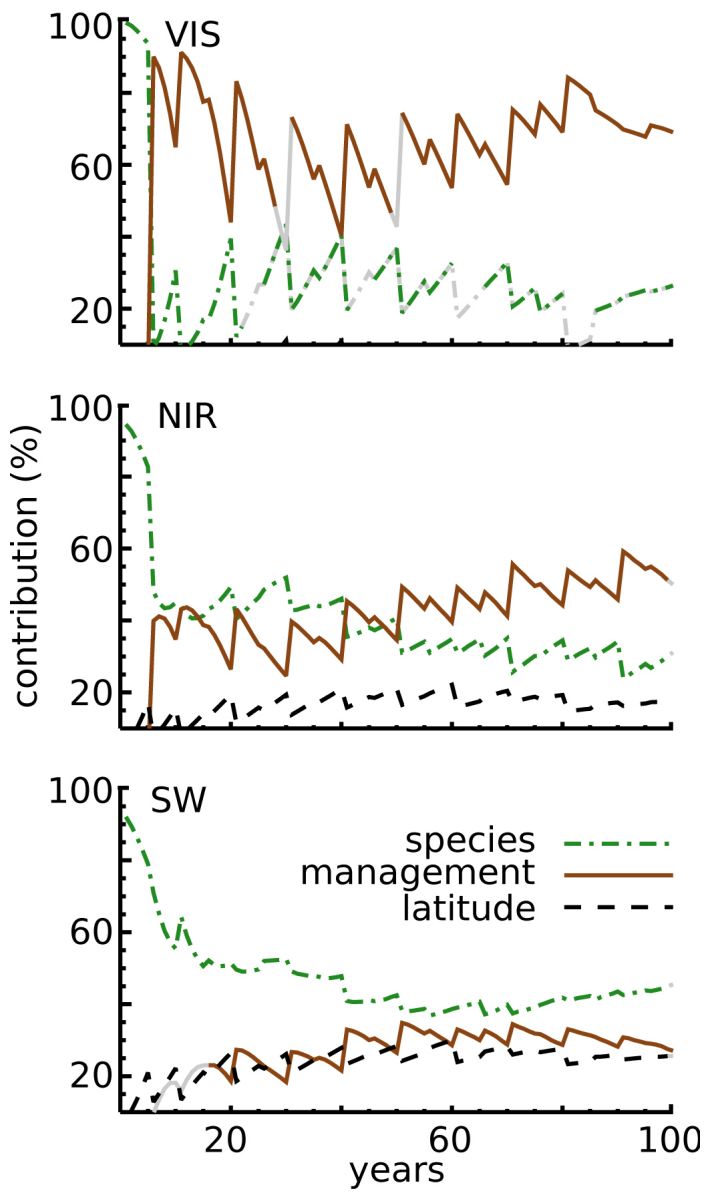

Fig. 4. Contribution (\%) of the factors species, management and latitude to the total variance of albedo (June) in visible (VIS), nearinfrared (NIR) and the shortwave (SW) wavelength bands. Only contributions larger than $10 \%$ are shown. The grey line segments indicate non-significant contributions $(p>0.01)$. Contributions of the interaction terms do not exceed $10 \%$.

summertime canopy albedo. Surprisingly, latitude only plays a role in the near-infrared band, where it contributes about $20 \%$ to the total variance.

The contributing factors differ depending on whether the visible and near-infrared wavelength bands are treated separately or whether they are combined in a single so-called shortwave canopy albedo. This change in explanatory factors is because absorption in the visible band reaches its maximum when the absorption for the near-infrared band reaches its minimum. Hence the sum of both spectra shows substantially less variation than the individual spectra. The variation in shortwave summertime albedo is driven by tree species. This effect decreases towards the end of the forest rotation to about $40 \%$, whereas the contributions of thinning and latitude increase and explain the rest of the variation equally with about $25 \%$ each.
There were no significant interactions between species and thinning observed that explain more than $10 \%$ of the variation in canopy albedo.

\subsection{How does species affect summertime canopy albedo?}

Across all four thinning strategies, the summertime visible canopy albedo of all species ranges from 0.03 to 0.06 (Fig. 5) over one forest rotation. In the near-infrared summertime canopy albedo of pine ranges between 0.20 and 0.27 . Beech and oak show a smaller temporal variability compared to pine, which only ranges between 0.24 and 0.28 . The opposite temporal variabilities in the visible and near-infrared wavelength bands largely offset one another when the temporal variability in shortwave canopy albedo is considered (Fig. 5).

Every simulation was performed for 1 ha $\left(10000 \mathrm{~m}^{2}\right)$ of forest. Subsequently, this 1 ha was divided into 25 squares $(20 \mathrm{~m} \times 20 \mathrm{~m})$ and the albedo was simulated for each square separately. For dense forest, the albedo of a single $20 \mathrm{~m} \times 20 \mathrm{~m}$ subplot is similar to the albedo of the entire 1 ha plot as shown by the small variability in Fig. 5. Contrary to this, moderately sparse (cover circa 0.5 ) canopies showed a considerable spatial variability within the 1 ha plot. At the end of the rotation, however, the very sparse canopies were again well represented by single $20 \mathrm{~m} \times 20 \mathrm{~m}$ subplots.

\subsection{How does thinning affect the summertime canopy albedo?}

In the case of the unmanaged forest, during stand establishment the summertime canopy albedo decreases in the visible spectrum and increases in the near-infrared spectrum. After this period of about 15-20 years the canopy is closed and the albedo stays constant. Thinning strategies, however, lead to a non-monotonic variation in summertime albedo over the forest rotation period compared to unmanaged forest (Fig. 5). The analysis reveals a tendency for more intensive thinning strategies to have a stronger effect on summertime canopy albedo. After stand establishment, the summertime near-infrared albedo drops by up to $22 \%$ in the case of intense thinning of pine forest compared to the simulation without thinning. The drop is only half this amount for the beech and oak stands. After every thinning event, canopy albedo increases in the visible band and decreases in the nearinfrared wavelength band. Thinning lowered the summertime shortwave canopy albedo compared to unmanaged forest (Fig. 6a). Interestingly, the thinning strategy "intense thinning" reduces the summertime albedo slightly more than the thinning strategy labelled 'strong thinning'. In total, the absolute maximum change in shortwave canopy albedo between managed and unmanaged forest stands ranges from 0.020 for pine and 0.015 for beech to 0.010 for oak. In the case of pure isotropic radiation (Fig. 6b), the albedo becomes independent of the solar zenith angle and light thinning strategies may 

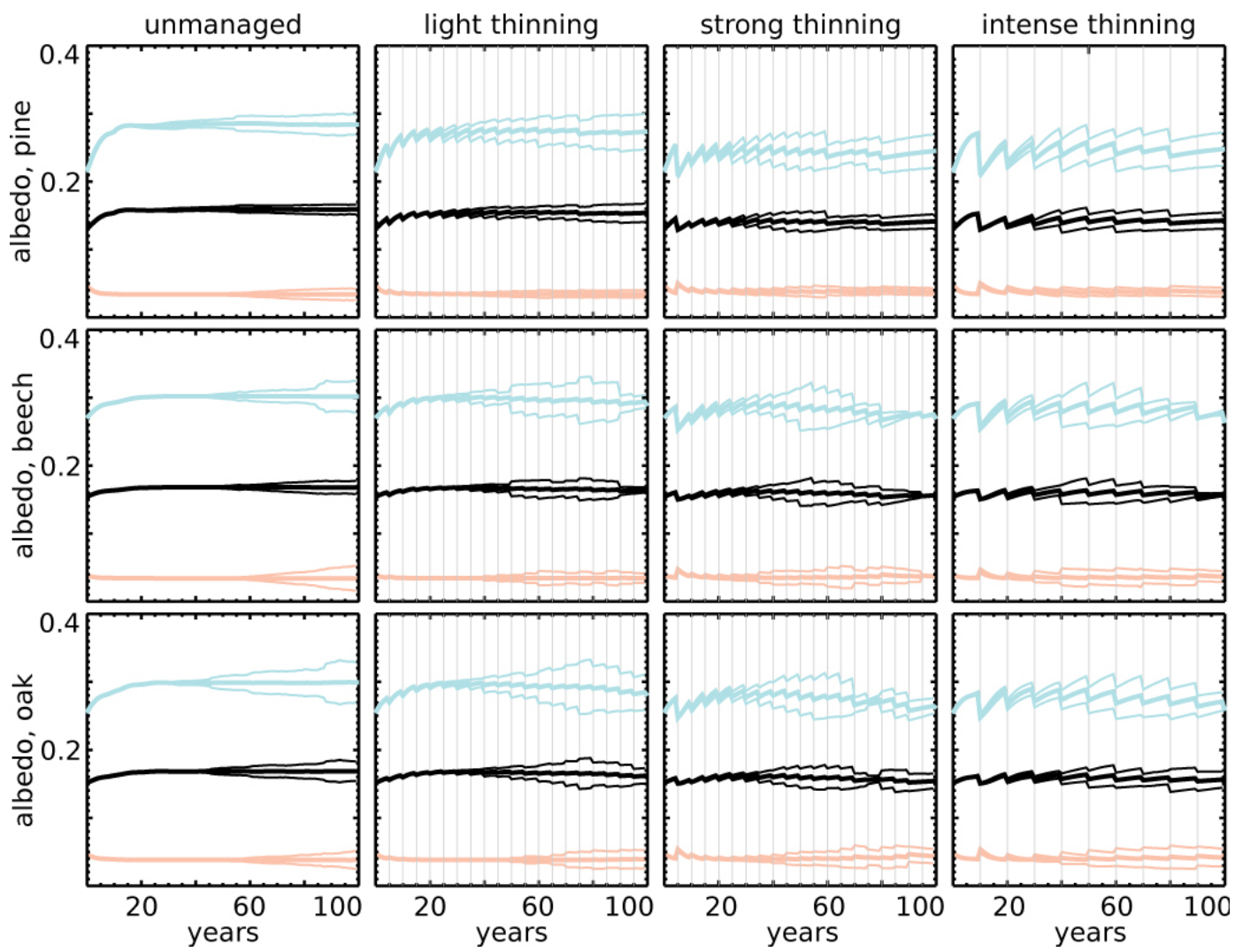

Fig. 5. Albedo (June) of three tree species and four management strategies at $50^{\circ} \mathrm{N}$ and with the maximum solar angle of $27.41^{\circ}$ at the summer solstice. The black line indicates shortwave, light red indicates visible albedo and light blue indicates near-infrared albedo. The thin lines represent one standard deviation of 25 simulations of $20 \times 20 \mathrm{~m}$ forest sub-plots.

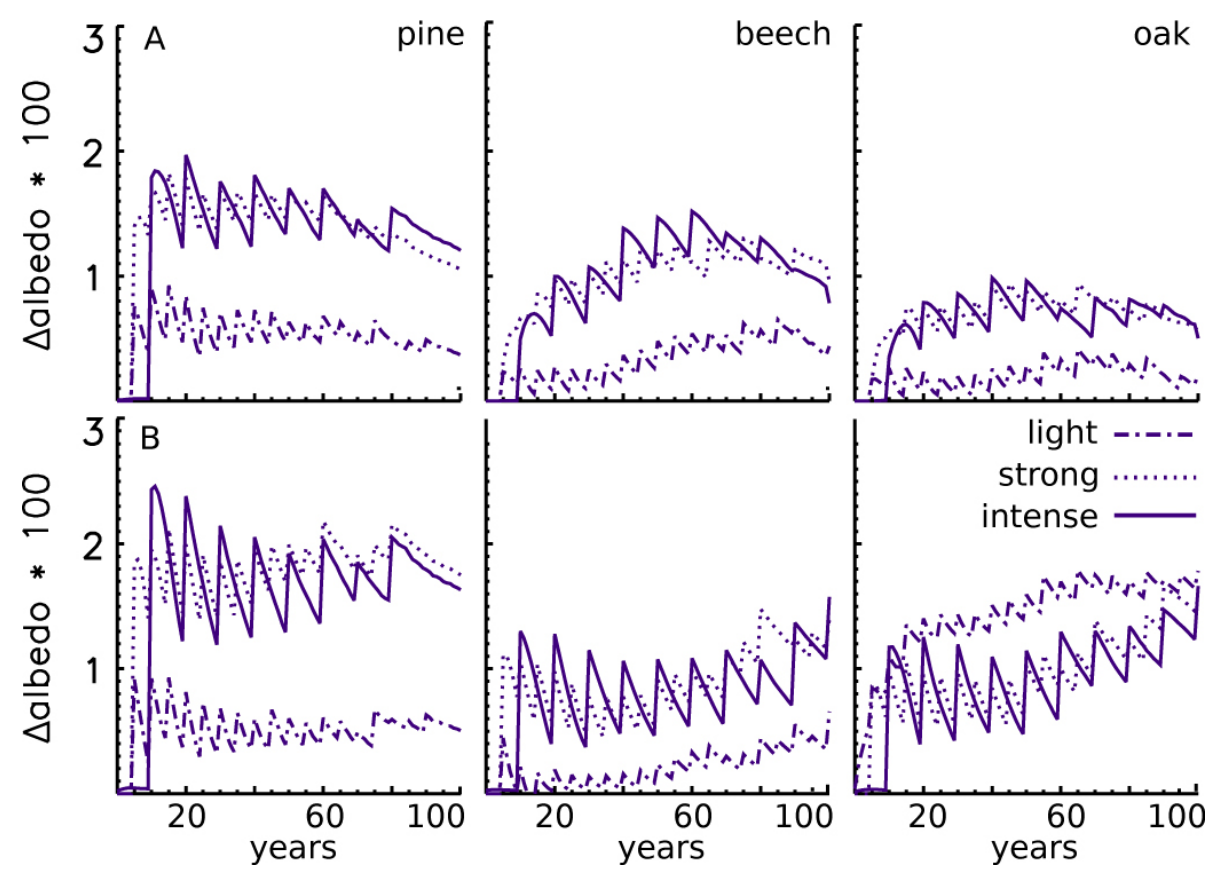

Fig. 6. Difference between shortwave albedo (June) of unmanaged forest and managed forest at $50^{\circ} \mathrm{N}$ (A) black-sky albedo and (B) white-sky albedo. Note that the albedo-difference values are multiplied by 100 for better visibility. 
now have a stronger effect on albedo than under anisotropic radiation.

\subsection{How does latitude affect summertime canopy albedo?}

The diurnal pattern of solar zenith angle at a given location is determined by the site's latitude. We compared the average summertime canopy albedo over one rotation period of each species and thinning type for the transect along the $9^{\circ} \mathrm{E}$ line of longitude from $40^{\circ}$ to $60^{\circ} \mathrm{N}$. Independent of the spectral band, species and thinning type, all simulations reveal a linear trend (Fig. 7a, shortwave albedo) with a strong positive correlation between latitude and albedo: i.e. the further north the forest stand is situated, the higher the summertime canopy albedo. This implies that forests with identical canopy structures will have different canopy albedo values due to their location. However, for pine, the difference between unmanaged and intensively managed forest remains at each latitude, whereas the deciduous forests exhibit a decreasing difference in albedo between managed and unmanaged stands from low to high latitudes (Fig. 7b). Thus the absolute summertime albedo values of the forest stands increase with increasing latitude, but the difference between unmanaged and managed forest decreases with increasing latitude.

\subsection{What drives changes in summertime canopy albedo?}

Crown volume and LAI are positively correlated (Fig. 8), with low crown volumes typically exhibiting low LAI. However, above a certain LAI threshold, the crown volume may further increase whereas LAI saturates. The exact value of the LAI threshold depends on the species and thinning strategy. Nevertheless, all forest types show that low LAIs correspond to low summertime canopy albedo values, with the albedo reaching its minimum as crown volume increases. The "saw-like" pattern in the albedo (Fig. 8) is not solely caused by changes in LAI but rather by changes in the crown volume (not shown). Crown volume is calculated as a cylinder using crown radius and crown height. It is the same in summer and winter, and it does not take account of any gaps within the crowns. Thus, both changes in LAI and crown volume seem to drive the canopy albedo.

\subsection{Do summertime albedo changes have an effect on the radiative forcing?}

The radiative forcing is calculated for the largest site-specific albedo changes in June that occur between the unmanaged and the intense forest strategy (Fig. 9) for the two extreme cases of black-sky albedo and white-sky albedo. For all three species, the integration of the radiation over a rotation results in a positive radiation forcing, and thus in a warming of the atmosphere. The mean radiative forcing resulting from black-sky albedo over rotation ranges from $1.09 \mathrm{Wm}^{-2}$ (oak forest at $50^{\circ} \mathrm{N}$ ) to $3.39 \mathrm{Wm}^{-2}$ (pine forest at $40^{\circ} \mathrm{N}$ ). However, the forcing is non-monotonic over the rotation; after each thinning event the radiative forcing increases up to $5.18 \mathrm{Wm}^{-2}$. For pine and oak, the radiative forcing is largest during the first half of a rotation, whereas beech reaches its maximum radiative forcing in the middle of a rotation. The radiative forcings of all species display a negative correlation with latitude: the radiative forcing decreases from low to high latitude (Fig. 9). This feature is less prominent in the case of white-sky albedo and the general signal is weaker. Only for the pine forest is the mean radiative forcing slightly stronger compared to the black-sky albedo. The mean blacksky albedo radiative forcing over a rotation ranges from $1.36 \mathrm{Wm}^{-2}$ (beech forest at $50^{\circ} \mathrm{N}$ ) to $3.92 \mathrm{Wm}^{-2}$ (pine forest at $40^{\circ} \mathrm{N}$ ), with the maximum increase after a thinning event at $6.08 \mathrm{Wm}^{-2}$.

\section{Discussion}

\subsection{Tendency to overestimate near-infrared albedo of needleleaf forest}

Optical sensors for measuring gap fractions, such as the one used at EE-Jär, often overestimate the gap fraction (Kobayashi et al., 2013); hence, our simulation may be closer to the true gap fraction than the observation. Furthermore, the assumption of cylinder-shaped crowns may have contributed to the model underestimating the observed gap fraction (Fig. 3).

Now that the gap fraction is excluded as a major cause of the deviation between simulations and observations, too high near-infrared single scattering albedo values for pine, as obtained from the JRC-TIP product, are left as the most likely cause. In the case of a closed canopy the top-of-the-canopy albedo is determined by the effective single scattering albedo and direction of scattering values, whereas in the absence of a canopy the albedo is determined by the true background values. In both cases, the JRC-TIP inversion used for the optimisation of these surface properties is well constrained. For a sparse canopy, the inversion also needs to optimise the true background albedo; this may lead to top-of-the-canopy albedos being correctly reproduced by several parameter combinations. Errors in true background albedo values may be compensated for by errors in the effective parameters. We believe this phenomenon is reflected in the validation results for NL-Loo and EE-Jar.

We calculated the near-infrared effective single scattering albedo that would have been needed to reproduce the sitelevel observed albedo of NL-Loo. The original near-infrared effective single scattering derived from the JRC-TIP package was 0.67 ; the estimated value to match near-infrared albedo of the site was 0.54 . Other approaches also report that the near-infrared scattering seems to be a challenging 


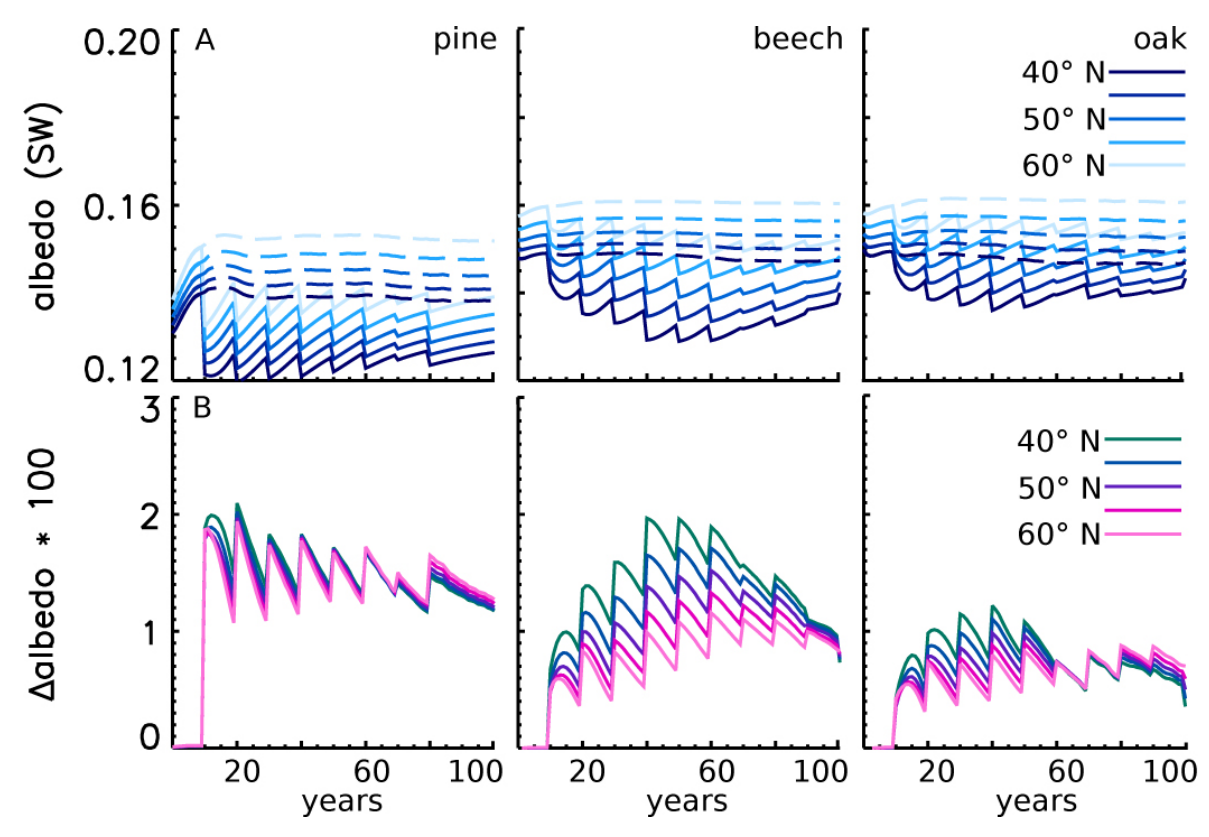

Fig. 7. Maximal difference between shortwave albedo (June) of unmanaged forest and managed forest occurs in the case of intensely managed forest. This difference is shown for each species and for the transect along $9^{\circ} \mathrm{E}$ stretching from $40^{\circ}$ to $60^{\circ} \mathrm{N}$ in discrete $5^{\circ}$ steps. The brighter the colour, the further north the albedo is calculated. Upper panel (A) shows shortwave albedo of unmanaged forest (staggered line) and intensely managed forest (smooth line). Lower panel (B) shows the difference between the two management strategies (unmanaged-intense). Note the albedo values are multiplied by 100 for better visibility.

parameter to estimate correctly (Kuusk et al., 2010). We derived this value for NL-Loo but when applied at EE-Jär the near-infrared albedo decreased from the initial 0.23 to 0.17 , which differs by only 0.01 from the observed value. This result confirms our belief that the observed deviation is not due to a shortcoming in the model itself but reflects the difficulties the JRC-TIP has with optimising parameter values in the absence of field observations in the specific case of a sparse canopy.

In addition, scale issues cannot be ruled out as a possible cause of the mismatch between observations and simulations. The albedo of sparse needleleaf forest seems to be challenging, not only to model (Kuusk et al., 2010) but also to observe (Davidson and Wang, 2004). The Forest Radiative Transfer model (FRT) overestimated the reflectance spectra for EE-Jär in the near-infrared domain by up to 0.04 (Kuusk et al., 2010). We simulate the albedo for a forest stand of a size of $1 \mathrm{ha}$, whereas the footprint of the site observations range from a few square metres (UAVSpec (Unmanned Aerial Vehicle Spectrometer system)) to $1200 \mathrm{~m}^{2}$ (albedometer). Local measurements of sparse needleleaf forests underestimated the shortwave albedo considerably, in the case of snow on the ground by up to 0.3 (Davidson and Wang, 2004). This is due to the spatial heterogeneity inherent in point-topixel inter-comparison (Cescatti et al., 2012; Román et al., 2009).

Our model chain tends to overestimate the near-infrared summertime albedo of needleleaf forest, but we considered this bias insufficient to hamper the use of the model for the factorial simulations presented in the next section, especially because the remainder of the study compares different treatments and thus discusses changes in summertime albedo rather than absolute albedo values.

\subsection{Thinning intensity as a driver of summertime albedo}

Forest summertime shortwave canopy albedo is determined by: (a) the single scattering albedo, which is a biophysical property of the leaves and needles, and (b) canopy structure (i.e. crown volume and LAI), which is mainly determined by the functional group, tree location within the stand and growing conditions. Our simulations confirm the dependency of canopy albedo on these natural drivers, but add insight into how these natural processes are altered by humans through forest thinning.

Effective single scattering albedo and its direction in both the visible and near-infrared wavelength bands were observed to be remarkably similar across tree species and even between broadleaved and needleleaved species (Table 2). Despite the similarities in these physical leaf properties, the canopy albedo has been repeatedly reported to differ between forest stands composed of different tree species, hinting at the importance of the canopy structure and background albedo as determinants of the canopy albedo. The similarity in effective single scattering albedo and scattering direction 

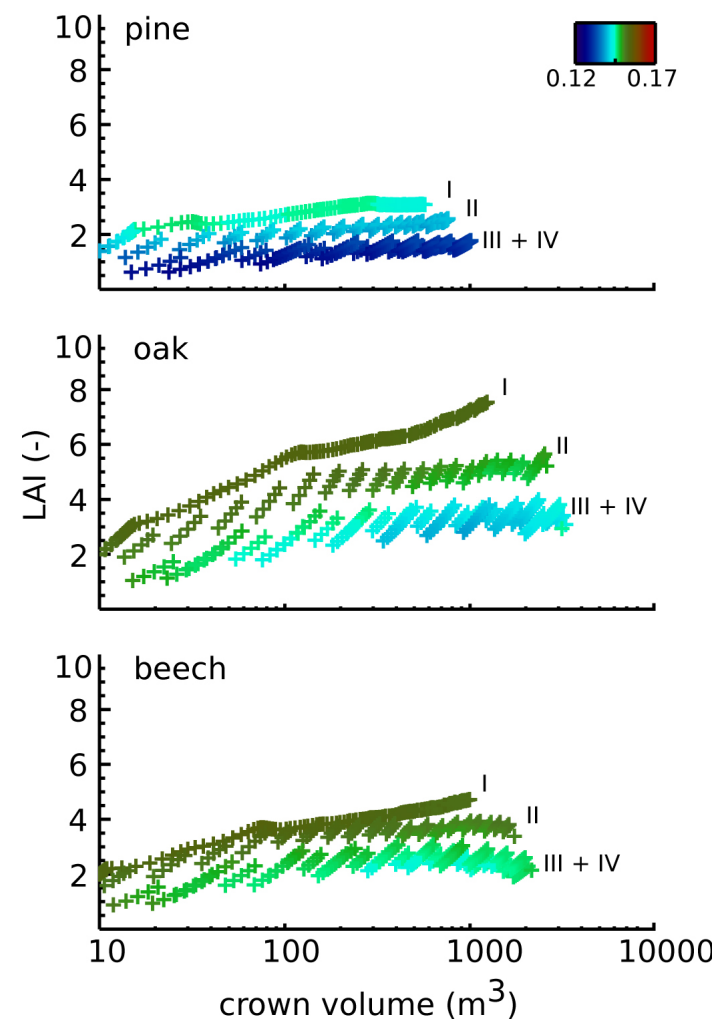

Fig. 8. Canopy albedo (June) as a function of stand crown volume $\left(\mathrm{m}^{3}\right)$ and stand LAI (-). Crown volume is defined as a cylinder using crown radius and crown height for its calculation. The colour scale indicates the respective shortwave albedo value. For this analysis the results for all management strategies were pooled per tree species; the Roman numerals indicate the management strategy (see caption Table 1). Note the logarithmic $x$ axis.

for the main European forest tree species is in contrast to the substantial differences in these properties between, for example, forest and herbaceous plants (Asner, 1998). We found no references contributing to an explanation of the observed similarities of woody plants or the differences between woody and herbaceous plants in single leaf scattering and scattering direction. The differences and similarities in the aforementioned leaf properties are plant traits that correlate with other traits such as leaf angle (Ollinger, 2011), leaf to shoot clumping (Smolander and Stenberg, 2003), leaf element composition (Hollinger et al., 2010) or structural parameters of the canopy (Wicklein et al., 2012) to jointly optimise leaf temperature and light harvesting.

Variation in LAI is often considered a natural process driven by phenology (Betts and Ball, 1997; Bonan et al., 2011), which in turn is the outcome of natural succession (Amiro et al., 2006; McMillan and Goulden, 2008). Hence, LAI is a widely used descriptor of canopy structure, and it is the sole driver of albedo in several land surface models (Loew et al., 2013; de Noblet-Ducoudré et al., 1993; Otto et al., 2011). Our analysis confirms that canopy albedo relates to LAI as previously reported by others (Kuusk et al., 2012; Rautiainen et al., 2011) but this is only a partial relationship. Canopy structure as a whole determines scattering and absorption (Wicklein et al., 2012) by, for example, influencing the depth at which rays first encounter foliage and the probability that after this initial interaction the reflected rays will interact with leaves located deeper in the canopy or with the forest floor below the canopy.

Thinning aims at creating a more uniform tree spacing; consequently, after thinning there will be less overlap between tree crowns and individual trees will fill the crown layer more uniformly than before. Thinning activities are likely to affect both LAI and crown volume (Fig. 8) through changes in tree spacing, stand density and size distribution. Subsequently, the remaining amount of LAI per crown volume determines how much light arrives at the forest floor. A sparse canopy cover allows more light to penetrate to the forest floor than a more complete cover and the former is therefore more likely to support an abundant understorey vegetation (Ares et al., 2010; Foré et al., 1997). When the albedo of the understorey vegetation exceeds the albedo of the tree canopy above, a low value of canopy cover is likely to result in a higher albedo compared to a stand with high canopy cover. Hence, LAI, canopy volume and background (i.e. understorey) albedo are all needed to model thinning-induced changes in canopy albedo.

Beside the physical parameters determining canopy albedo of forests, the variation of canopy albedo is often explained as a function of forest age (e.g. McMillan et al., 2008; Nilson and Peterson, 1994). However, the correlation with forest age is most likely spurious because there is no physical univariate relationship between age and albedo. This relationship should only be applied during stand establishment when the changes in foliage composition evolve with time, i.e. when a homogeneous grass layer is replaced by a heterogeneous tree layer where foliage is aggregated into tree crowns. Further, the relationship no longer holds if the forest is thinned: our simulations show that during stand establishment, summertime albedo is driven by tree species. After establishment, the effect of tree species on albedo decreases in favour of an increasing importance of forest thinning on canopy albedo. These trends continue until the end of the rotation where forest thinning finally explains up to $70 \%$ of the variance in (visible) canopy albedo. Hence, thinning makes a considerable contribution to the variations in canopy albedo and decouples stand age from forest albedo.

\subsection{The effects of forest thinning on summertime albedo}

Thinning-driven variations in summertime canopy albedo amount in absolute terms to up to 0.02 , with the largest changes being induced by intensive thinning strategies. In textbooks, the shortwave albedo of different deciduous forests ranges between $0.15-0.20$ and for needleleaf forest from 0.05-0.15 (e.g. Gao, 2005; Lucht et al., 2000; Oke, 


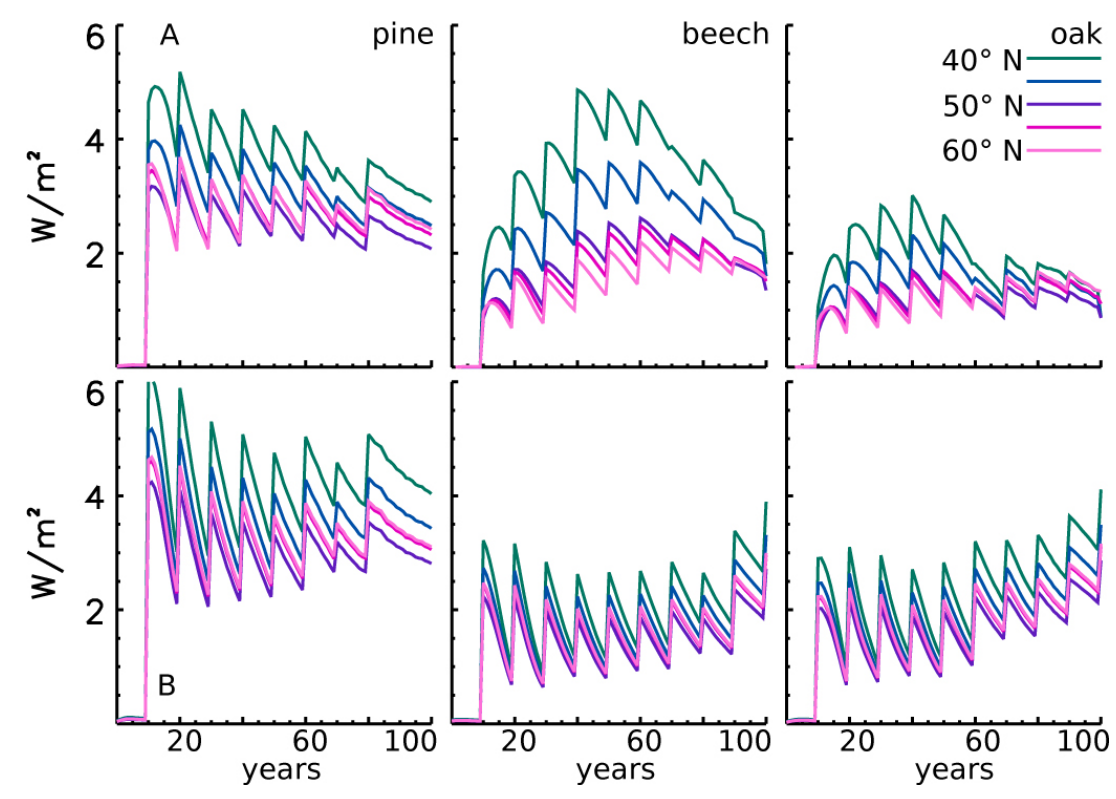

Fig. 9. Local radiative forcing for June calculated over a rotation for all three species and resulting from the difference between unmanaged and intensely thinned forest for the transect along the line of longitude at $9^{\circ} \mathrm{E}$ stretching from $40^{\circ}$ to $60^{\circ} \mathrm{N}$ in discrete $5^{\circ}$ steps. The upper row (A) shows the radiative forcing for the black-sky albedo; the lower row (B) shows the radiative forcing for the case of white-sky albedo.

1987). The range is usually explained by different species (e.g. Davidson and Wang, 2004) and solar zenith angles (e.g. Dickinson et al., 1993). However, these values are reported without specifying the applied thinning strategy and time of rotation. Thus, as much as 20 to $50 \%$ of this range may be the result of thinning-induced changes in forest structure.

Observations show opposing effects of thinning on albedo: measurements in a ponderosa pine stand (Dore et al., 2012) and in a maritime pine plantation (Moreaux et al., 2011) have reported that thinning slightly increases the summertime canopy albedo. Measurements of a loblolly pine plantation showed a decrease of summer canopy albedo due to thinning (Sun et al., 2010). These conflicting results may be due to different stand structures (see above), regrowth of understorey layer (Ares et al., 2010) or due to changes in the water balance (Sun et al., 2010). A modelling study indicates that regular thinning of coniferous boreal forest stands reduces summer albedo (Rautiainen et al., 2011). In addition, we have shown that this finding may also apply to deciduous forests, independent of their location.

Increasing sequestration of atmospheric carbon dioxide through forest management is considered to be one of the instruments available to mitigate climate change (UN, 1998). Our analysis shows that thinning, which is one aspect of forest management, will not only affect the greenhouse gas balance but will also impact the forest albedo. The concept of radiative forcing (Hansen et al., 1997) is one way to quantify the local per-unit area climate impacts of forest thinning. Despite the removal of individual trees, moving from a natural unthinned forest to a thinned forest results in a decreas- ing summertime albedo and atmospheric warming of at most $5 \mathrm{Wm}^{-2}$ (June); this is due to more uniform filling of the crown volume (see above) with leaves or needles. The complete cutting of trees, however, removes the entire canopy and thus presumably would have the opposite effect. Indeed, a negative radiative forcing of up to $-18 \mathrm{Wm}^{-2}$ in summer was measured from clear-cutting in the temperate zone (Houspanossian et al., 2013).

Our study is restricted to albedo changes and radiative forcing in June and therefore the results are probably more relevant for local than for global climate, i.e. the effect of thinning on summer albedo may enhance local summer temperatures. For global climate, the results should include cloudy conditions and be integrated over all four seasons, because thinning-induced effects on albedo - and on the magnitude of radiative forcing - may differ when snow is on the forest floor (Manninen and Stenberg, 2009). The effects of differences in albedo and the magnitude of radiative forcing may differ on a seasonal and annual basis, possibly leading to different effects along with the time period over which the effects are considered (Kirschbaum et al., 2011). These reasons provide a rationale for Earth system models to extend their capacity to include modelling the effects of forest management and anthropogenic land management in general.

\subsection{Climate effects of thinning}

Observations showed that changes in albedo due to thinning did not consistently alter soil temperature or net radiation (Dore et al., 2012; Moreaux et al., 2011). This lack of response could be caused by a change in outgoing long-wave 
radiation offsetting the albedo effect (Moreaux et al., 2011). Another reason could be a difference in canopy wetness after rainfall or lower sensitivity to soil water availability (Moreaux et al., 2011). However, indirect climatic effects linked to changes in canopy albedo or other biophysical properties cannot be quantified without more comprehensive models. The local radiative forcing (Fig. 9) provides us only with a rough estimate of how the albedo changes resulting from forest thinning may impact the climate.

\subsection{Spatial application of model approach}

In its most basic form, forest management interacts with the stand structure through two processes: changing the tree species composition (long-term strategy, covering more than several decades) and changing stand diameter distribution through thinning (short-term strategy, less than several decades). Both processes affect the structure of the canopy and thus the organisation in space and time of the bulk plant components (Parker, 1995). This study shows that species selection and different thinning strategies exert a roughly similar control over summertime canopy albedo (see Table 4). The effect of the solar zenith angle on the black-sky canopy albedo is of the same order of magnitude. This implies that the albedo needs to be simulated as a function of the solar zenith angle and that, given the similarities in the effective scatter parameters, canopy structure at least needs to be parameterised at the species level. Thinning does not need to be explicitly implemented in Earth system models but it needs be expressed as, at least, changes in leaf area index and crown volume. These findings imply that changes to the structure of Earth system models are required for more accurate and computationally efficient canopy radiation transfer calculations.

The 1-D modelling approach presented here could be implemented in Earth system models. The simulations of the forest properties provided by the forest gap model ForGEM could be replaced by the process-based global vegetation models that are already included in several Earth system models. Most likely, the existing vegetation model will need to be extended by a semi-explicit or statistical forest management module that simulates forest growth and management (Bellassen et al., 2010). These modules would then calculate the changes in LAI and crown volume.

The LAI is non-linearly correlated with the height of the trees and the canopy closure (not shown) and needs to be transformed into a solar-zenith-angle-dependent effective LAI to represent the structure of the canopy in the 1-D canopy transfer model. Different approaches have been proposed to relate LAI to effective LAI (Haverd et al., 2012; NiMeister et al., 2010). The 1-D radiation transfer used in this study (Pinty et al., 2006) is computationally fast and requires only a small number of input parameters, whereas global effective scattering parameters are provided by the JRC-TIP package (Pinty et al., 2011a).
Applying the model adjustments discussed above to an Earth system model would give a tool that could be applied to produce a comprehensive assessment of the effect of forest management on climate. These adjustments are currently being incorporated into ORCHIDEE (ORganizing Carbon and Hydrology In Dynamic EcosystEms, Krinner 2005), the land surface scheme of the IPSL (Institut Pierre Simon Laplace) Earth system model.

Acknowledgements. We would like to thank Miina Rautiainen for useful comments on an earlier draft of the manuscript. J. Otto and S. Luyssaert were funded through ERC starting grant 242564 and received additional funding through FWO-Vlaanderen and COST ES0805 TERRABITES.

Edited by: G. Wohlfahrt

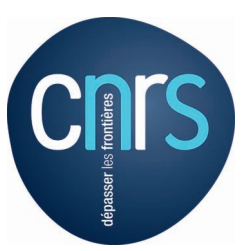

The publication of this article is financed by CNRS-INSU.

\section{References}

Amiro, B. D., Orchansky, a. L., Barr, a. G., Black, T. a., Chambers, S. D., Chapin III, F. S., Goulden, M. L., Litvak, M., Liu, H. P., McCaughey, J. H., McMillan, A., and Randerson, J. T.: The effect of post-fire stand age on the boreal forest energy balance, Agr. Forest Meteorol., 140, 41-50, doi:10.1016/j.agrformet.2006.02.014, 2006.

Anderson, R. G., Canadell, J. G., Randerson, J. T., Jackson, R. B., Hungate, B. a, Baldocchi, D. D., Ban-Weiss, G. a, Bonan, G. B., Caldeira, K., Cao, L., Diffenbaugh, N. S., Gurney, K. R., Kueppers, L. M., Law, B. E., Luyssaert, S., and O'Halloran, T. L.: Biophysical considerations in forestry for climate protection, Front. Ecol. Environ., 9, 174-182, doi:10.1890/090179, 2011.

Ares, A., Neill, A. R., and Puettmann, K. J.: Understory abundance, species diversity and functional attribute response to thinning in coniferous stands, Forest Ecol. Manage., 260, 1104-1113, doi:10.1016/j.foreco.2010.06.023, 2010.

Asner, G. P.: Biophysical and biochemical sources of variability in canopy reflectance, Remote Sens. Environ., 64, 234-253, doi:10.1016/S0034-4257(98)00014-5, 1998.

Bala, G., Caldeira, K., Wickett, M., Phillips, T. J., Lobell, D. B., Delire, C., and Mirin, A.: Combined climate and carbon-cycle effects of large-scale deforestation, Proceedings of the National Academy of Sciences of the United States of America, 104, 6550-5, 2007.

Bathiany, S., Claussen, M., Brovkin, V., Raddatz, T., and Gayler, V.: Combined biogeophysical and biogeochemical effects of largescale forest cover changes in the MPI earth system model, Biogeosciences, 7, 1383-1399, doi:10.5194/bg-7-1383-2010, 2010.

Bellassen, V., Le Maire, G., Dhôte, J. F., Ciais, P., and Viovy, N.: Modelling forest management within a global vegetation model-Part 1: Model structure and general behaviour, Ecol. 
Modell., 221, 2458-2474, doi:10.1016/j.ecolmodel.2010.07.008, 2010.

Betts, A. K. and Ball, J. H.: Albedo over the boreal forest, J. Geophys. Res., 102, 28901-28909, 1997.

Betts, R. A.: Offset of the potential carbon sink from boreal forestation by decreases in surface albedo., Nature, 408, 187-90, doi:10.1038/35041545, 2000.

Bonan, G. B., Lawrence, P. J., Oleson, K. W., Levis, S., Jung, M., Reichstein, M., Lawrence, D. M., and Swenson, S. C.: Improving canopy processes in the Community Land Model version 4 (CLM4) using global flux fields empirically inferred from FLUXNET data, J. Geophys. Res., 116, 1-22, doi:10.1029/2010JG001593, 2011.

Bréda, N. J. J.: Ground-based measurements of leaf area index: a review of methods, instruments and current controversies, J. Experiment. Botan., 54, 2403-17, doi:10.1093/jxb/erg263, 2003.

Bright, R. M., Cherubini, F., and Strømman, A. H.: Climate impacts of bioenergy: Inclusion of carbon cycle and albedo dynamics in life cycle impact assessment, Environ. Impact Assess. Rev., 37, 2-11, doi:10.1016/j.eiar.2012.01.002, 2012.

Brus, D. J., Hengeveld, G. M., Walvoort, D. J. J., Goedhart, P. W., Heidema, A. H., Nabuurs, G. J., and Gunia, K.: Statistical mapping of tree species over Europe, Europ. J. Forest Res., 131, 145157, doi:10.1007/s10342-011-0513-5, 2011.

Cescatti, A., Marcolla, B., Santhana Vannan, S. K., Pan, J. Y., Román, M. O., Yang, X., Ciais, P., Cook, R. B., Law, B. E., Matteucci, G., Migliavacca, M., Moors, E., Richardson, A. D., Seufert, G. and Schaaf, C. B.: Intercomparison of MODIS albedo retrievals and in situ measurements across the global FLUXNET network, Remote Sens. Environ., 121, 323-334, doi:10.1016/j.rse.2012.02.019, 2012.

Chen, J. M.: Optically-based methods for measuring seasonal variation of leaf area index in boreal conifer stands, Agr. Forest Meteorol., 80, 135-163, doi:10.1016/0168-1923(95)02291-0, 1996.

Cherubini, F., Bright, R. M., and Strømman, A. H.: Site-specific global warming potentials of biogenic $\mathrm{CO}_{2}$ for bioenergy: contributions from carbon fluxes and albedo dynamics, Environ. Res. Lett., 7, 045902, doi:10.1088/1748-9326/7/4/045902, 2012.

Condés, S. and Sterba, H.: Derivation of compatible crown width equations for some important tree species of Spain, Forest Ecol. Manage., 217, 203-218, doi:10.1016/j.foreco.2005.06.002, 2005.

Davidson, A. and Wang, S.: The effects of sampling resolution on the surface albedos of dominant land cover types in the North American boreal region, Remote Sens. Environ., 93, 211-224, doi:10.1016/j.rse.2004.07.005, 2004.

Dickinson, R. E., Henderson-Sellers, A., and Kennedy, P. J.: Biosphere-Atmosphere Transfer Scheme ( BATS ) Version le as Coupled to the NCAR Community Climate Model, NCAR Technical Note, NCAR/TN-38(August), 1993.

Dore, S., Montes-Helu, M., Hart, S. C., Hungate, B. a., Koch, G. W., Moon, J. B., Finkral, A. J. and Kolb, T. E.: Recovery of ponderosa pine ecosystem carbon and water fluxes from thinning and stand-replacing fire, Global Change Biol., 18, 3171-3185, doi:10.1111/j.1365-2486.2012.02775.x, 2012.

Fontes, L., Bontemps, J., and Bugmann, H.: Models for supporting forest management in a changing environment, Forest Systems, 19, 8-29, 2010.
Foré, S. A., Vankat, J. L., and Schaefer, R. L.: Temporal variation in the woody understory of an old-growth Fagus-Acer forest and implications for overstory recruitment, J. Veget. Sci., 8, 607-614, doi: $10.2307 / 3237364,1997$.

Gao, F.: MODIS bidirectional reflectance distribution function and albedo Climate Modeling Grid products and the variability of albedo for major global vegetation types, J. Geophys. Res., 110, D01104, doi:10.1029/2004JD005190, 2005.

Hansen, J., Sato, M., and Ruedy, R.: Radiative forcing and climate response, J. Geophys. Res.-Atmos., 102, 6831-6864, doi:10.1029/96JD03436, 1997.

Haverd, V., Lovell, J. L., Cuntz, M., Jupp, D. L. B., Newnham, G. J., and Sea, W.: The Canopy Semi-analytic Pgap And Radiative Transfer (CanSPART) model: Formulation and application, Agric. For. Meteorol., 160, 14-35, doi:10.1016/j.agrformet.2012.01.018, 2012.

Hollinger, D. Y., Ollinger, S. V., Richardson, a. D., Meyers, T. P., Dail, D. B., Martin, M. E., Scott, N. A., Arkebauer, T. J., Baldocchi, D. D., Clark, K. L., Curtis, P. S., Davis, K. J., Desai, A. R., Dragoni, D., Goulden, M. L., Gu, L., Katul, G. G., Pallardy, S. G., Paw U, K. T., Schmid, H. P., Stoy, P. C., Suyker, A. E., and Verma, S. B.: Albedo estimates for land surface models and support for a new paradigm based on foliage nitrogen concentration, Glob. Change Biol., 16, 696-710, doi:10.1111/j.13652486.2009.02028.x, 2010.

Houspanossian, J., Nosetto, M., and Jobbágy, E. G.: Radiation budget changes with dry forest clearing in temperate Argentina, Glob. Change Biol., 19, 1211-1222, doi:10.1111/gcb.12121, 2013.

Jansen, J. J., Sevenster, J., and Faber, J.: Opbrengsttabellen voor belangrijke boomsoorten in Nederland, IBN-rapport 221. Hinkeloord Report 17. DLO-Instituut voor Bos- en Natuuronderzoek; Landbouwuniversiteit, Wageningen. 202 p, IBN, Instituut voor Bos- en Natuuronderzoek, Institute for Forestry and Nature Research., 1996.

Kirschbaum, M. U. F., Whitehead, D., Dean, S. M., Beets, P. N., Shepherd, J. D., and Ausseil, A.-G. E.: Implications of albedo changes following afforestation on the benefits of forests as carbon sinks, Biogeosciences, 8, 3687-3696, doi:10.5194/bg-83687-2011, 2011.

Kobayashi, H., Ryu, Y., Baldocchi, D. D., Welles, J. M., and Norman, J. M.: On the correct estimation of gap fraction: How to remove scattered radiation in gap fraction measurements?, Agric. For. Meteorol., 174-175, 170-183, doi:10.1016/j.agrformet.2013.02.013, 2013.

Kramer, K., Buiteveld, J., Forstreuter, M., Geburek, T., Leonardi, S., Menozzi, P., Povillon, F., Schelhaas, M.-J., Teissier du Cros, E., Vendramin, G. G., and Van der Werf, D. C.: Bridging the gap between ecophysiological and genetic knowledge to assess the adaptive potential of European beech, Ecol. Modell., 216, 333353, doi:10.1016/j.ecolmodel.2008.05.004, 2008.

Krinner, G.: A dynamic global vegetation model for studies of the coupled atmosphere-biosphere system, Global Biogeochem. Cycles, 19, doi:10.1029/2003GB002199, 2005.

Kuusk, A. and Nilson, T.: A directional multispectral forest reflectance model, Remote Sens. Environ., 252, 244-252, 2000.

Kuusk, A., Kuusk, J., and Lang, M.: A dataset for the validation of reflectance models, Remote Sens. Environ., 113, 889-892, doi:10.1016/j.rse.2009.01.005, 2009. 
Kuusk, A., Nilson, T., Kuusk, J., and Lang, M.: Reflectance spectra of RAMI forest stands in Estonia: Simulations and measurements, Remote Sens. Environ., 114, 2962-2969, doi:10.1016/j.rse.2010.07.014, 2010.

Kuusk, J.: Measurement of forest reflectance, Top-of-canopy spectral reflectance of forests for developing vegetation radiative transfer models, 120 pp., Saarbrücken: Lambert Academic Publishing, 2011.

Kuusk, A., Lang, M., Kuusk, J., Lükk, T., Nilson, T., Mõttus, M., Rautiainen, M., and Eenmäe, A.: Database of optical and structural data for the validation of radiative transfer models, Tech. Rep., 03, 2012.

Kuusk, A., Lang, M., and Kuusk, J.: Database of optical and structural data for the validation of forest radiative transfer models, edited by: Kokhanovsky, A. A., Light Scattering Reviews 7: Radiative Transfer and Optical Properties of Atmosphere and Underlying Surface, 109-148, Springer, 2013.

Lenton, T. M. and Vaughan, N. E.: The radiative forcing potential of different climate geoengineering options, Atmos. Chem. Phys. Discuss., 9, 2559-2608, doi:10.5194/acpd-9-2559-2009, 2009.

Loew, A., van Bodegom, P. M., Widlowski, J.-L., Otto, J., Quaife, T., Pinty, B., and Raddatz, T.: Do we (need to) care about canopy radiation schemes in DGVMs? Caveats and potential impacts, Biogeosciences, 11, 1873-1897, doi:10.5194/bg-11-1873-2014, 2014.

Lucht, W., Schaaf, C. B. and Strahler, A. H.: An algorithm for the retrieval of albedo from space using semiempirical BRDF models, IEEE Transactions on Geosci. Remote Sens., 38, 977-998, doi:10.1109/36.841980, 2000.

Manninen, T. and Stenberg, P.: Simulation of the effect of snow covered forest floor on the total forest albedo, Agr. Forest Meteorol., 149, 303-319, doi:10.1016/j.agrformet.2008.08.016, 2009.

Martonchik, J. V, Bruegge, C. J., and Strahler, A. H.: A review of reflectance nomenclature used in remote sensing, Remote Sens. Rev., 19, 9-20, doi:10.1080/02757250009532407, 2000.

McMillan, A. M. S. and Goulden, M. L.: Age-dependent variation in the biophysical properties of boreal forests, Glob. Biogeochem. Cy., 22, 1-14, doi:10.1029/2007GB003038, 2008.

McMillan, A. M. S., Winston, G. C., and Goulden, M. L.: Age-dependent response of boreal forest to temperature and rainfall variability, Glob. Change Biol., 14, 1904-1916, doi:10.1111/j.1365-2486.2008.01614.x, 2008.

Moreaux, V., Lamaud, E., Bosc, A., Bonnefond, J.-M., Medlyn, B. E., and Loustau, D.: Paired comparison of water, energy and carbon exchanges over two young maritime pine stands (Pinus pinaster Ait.): effects of thinning and weeding in the early stage of tree growth., Tree Physiol., 31, 903-21, doi:10.1093/treephys/tpr048, 2011.

Nilson, T. and Peterson, U.: Age dependence of forest reflectance: Analysis of main driving factors, Remote Sens. Environ., 48, 319-331, doi:10.1016/0034-4257(94)90006-X, 1994.

Ni-Meister, W., Yang, W. and Kiang, N. Y.: A clumped-foliage canopy radiative transfer model for a global dynamic terrestrial ecosystem model. I: Theory, Agric. For. Meteorol., 150, 881894, doi:10.1016/j.agrformet.2010.02.009, 2010.

De Noblet-Ducoudré, N., Laval, K., and Perrier, A.: SECHIBA, a new set of parameterisations of the hydrologic exchanges at the land-atmosphere interface within the LMD Atmospheric General Circulation Model, J. Climate, 6, 248-273, 1993.
Oke, T. R.: Boundary layer climates, Second edi., Routledge, New York, 1987.

Ollinger, S. V: Sources of variability in canopy reflectance and the convergent properties of plants., New Phytol., 189, 375-94, doi:10.1111/j.1469-8137.2010.03536.x, 2011.

Otto, J., Raddatz, T., and Claussen, M.: Strength of forest-albedo feedback in mid-Holocene climate simulations, Clim. Past, 7, 1027-1039, doi:10.5194/cp-7-1027-2011, 2011.

Parker, G. G.: Structure and microclimate of forest canopies., in Forest Canopies., edited by: Lowman, M. D. and Nadkarni, N. M., 73-106, Academic Press, San Diego, CA., 1995.

Pielke, R. A. and Avissar, R.: Influence of landscape structure on local and regional climate, Landscape Ecology, 4, 133-155, doi:10.1007/BF00132857, 1990.

Pielke, R. A., Avissar, R. I., Raupach, M., Dolman, A. J., Zeng, X., and Denning, A. S.: Interactions between the atmosphere and terrestrial ecosystems: influence on weather and climate, Glob. Change Biol., 4, 461-475, 1998.

Pinty, B., Andredakis, I., Clerici, M., Kaminski, T., Taberner, M., Verstraete, M. M., Gobron, N., Plummer, S., and Widlowski, J.-L.: Exploiting the MODIS albedos with the Twostream Inversion Package (JRC-TIP): 1. Effective leaf area index, vegetation, and soil properties, J. Geophys. Res., 116, 1-20, doi:10.1029/2010JD015372, 2011a.

Pinty, B., Clerici, M., Andredakis, I., Kaminski, T., Taberner, M., Verstraete, M. M., Gobron, N., Plummer, S., and Widlowski, J.-L.: Exploiting the MODIS albedos with the Two-stream Inversion Package (JRC-TIP): 2. Fractions of transmitted and absorbed fluxes in the vegetation and soil layers, J. Geophys. Res., 116, 1-15, doi:10.1029/2010JD015373, 2011 b.

Pinty, B., Gobron, N., Widlowski, J.-L., Lavergne, T., and Verstraete, M. M.: Synergy between 1-D and 3-D radiation transfer models to retrieve vegetation canopy properties from remote sensing data, J. Geophys. Res., 109, 1-16, doi:10.1029/2004JD005214, 2004.

Pinty, B., Jung, M., Kaminski, T., Lavergne, T., Mund, M., Plummer, S., Thomas, E., and Widlowski, J.-L.: Evaluation of the JRC-TIP $0.01^{\circ}$ products over a mid-latitude deciduous forest site, Remote Sens. Environ., 115, 3567-3581, doi:10.1016/j.rse.2011.08.018, 2011c.

Pinty, B., Lavergne, T., Dickinson, R. E., Widlowski, J.-L., Gobron, N., and Verstraete, M. M.: Simplifying the interaction of land surfaces with radiation for relating remote sensing products to climate models, J. Geophys. Res., 111, 1-20, doi:10.1029/2005JD005952, 2006.

Pinty, B., Lavergne, T., Kaminski, T., Aussedat, O., Giering, R., Gobron, N., Taberner, M., Verstraete, M. M., Voßbeck, M., and Widlowski, J.-L.: Partitioning the solar radiant fluxes in forest canopies in the presence of snow, J. Geophys. Res., 113, D04104, doi:10.1029/2007JD009096, 2008.

Pinty, B., Andredakis, I., Clerici, M., Kaminski, T., Taberner, M., Verstraete, M. M., and Widlowski, J.-L.: Exploiting the MODIS albedos with the Two-stream Inversion Package (JRC-TIP): 1. Effective leaf area index, vegetation, and soil properties, J. Geophys. Res., 116, 1-20. doi:10.1029/2010JD015372, 2011.

Pretzsch, H., Biber, P., and Ďurský, J.:. The single tree-based stand simulator SILVA: construction, application and evaluation, Forest Ecol. Manage., 162, 3-21, 2002. 
Raumonen, P., Kaasalainen, M., Åkerblom, M., Kaasalainen, S., Kaartinen, H., Vastaranta, M., Holopainen, M., Disney, M. and Lewis, P.: Fast Automatic Precision Tree Models from Terrestrial Laser Scanner Data, Remote Sens., 5, 491-520, doi:10.3390/rs5020491, 2013.

Rautiainen, M., Stenberg, P., Mottus, M., and Manninen, T.: Radiative transfer simulations link boreal forest structure and shortwave albedo, Boreal Environ. Res., 16, 91-100, 2011.

Robinson, D. A. and Kukla, G.: Albedo of a Dissipating Snow Cover, J. Climate Appl. Meteorol., 23, 1626-1634, doi:10.1175/1520-0450(1984)023<1626:AOADSC>2.0.CO;2, 1984.

Román, M. O., Schaaf, C. B., Woodcock, C. E., Strahler, A. H., Yang, X., Braswell, R. H., Curtis, P. S., Davis, K. J., Dragoni, D., Goulden, M. L., Gu, L., Hollinger, D. Y., Kolb, T. E., Meyers, T. P., Munger, J. W., Privette, J. L., Richardson, A. D., Wilson, T. B., and Wofsy, S. C.: Remote Sensing of Environment The MODIS (Collection V005) BRDF / albedo product: Assessment of spatial representativeness over forested landscapes, Remote Sens. Environ., 113, 2476-2498, doi:10.1016/j.rse.2009.07.009, 2009.

Schaaf, C. B., Gao, F., Strahler, A. H., Lucht, W., Li, X., Tsang, T., and Roy, D.: First operational BRDF, albedo nadir reflectance products from MODIS, Remote Sens. Environ., 83, 135-148, doi:10.1016/S0034-4257(02)00091-3, 2002.

Schelhaas, M.-J.: The wind stability of different silvicultural systems for Douglas-fir in the Netherlands: a model-based approach, Forestry, 81, 399-414, doi:10.1093/forestry/cpn028, 2008.

Schelhaas, M.-J., Kramer, K., Peltola, H., Van der Werf, D. C. and Wijdeven, S. M. J.: Introducing tree interactions in wind damage simulation, Ecol. Modell., 207, 197-209, doi:10.1016/j.ecolmodel.2007.04.025, 2007.
Schwaiger, H. P. and Bird, D. N.: Integration of albedo effects caused by land use change into the climate balance: Should we still account in greenhouse gas units, Forest Ecol. Manage., 260, 278-286, doi:10.1016/j.foreco.2009.12.002, 2010.

Smolander, S. and Stenberg, P.: A method to account for shoot scale clumping in coniferous canopy reflectance models, Remote Sens. Environ., 88, 363-373, doi:10.1016/j.rse.2003.06.003, 2003.

Sun, G., Noormets, A., and Gavazzi, M.: Energy and water balance of two contrasting loblolly pine plantations on the lower coastal plain of North Carolina, USA, Forest Ecol. Manage., 259, 12991310, 2010.

UN: Kyoto Protocol to the United Nations Framework Convention on Climate Change, 1998.

Vermote, E. F., Tanre, D., Deuze, J. L., Herman, M., and Morcette, J.-J.: Second Simulation of the Satellite Signal in the Solar Spectrum, 6S: an overview, IEEE T. Geosci. Remote, 35, 675-686, doi:10.1109/36.581987, 1997.

Wicklein, H. F., Ollinger, S. V, Martin, M. E., Hollinger, D. Y., Lepine, L. C., Day, M. C., Bartlett, M. K., Richardson, A. D., and Norby, R. J.: Variation in foliar nitrogen and albedo in response to nitrogen fertilization and elevated $\mathrm{CO}_{2}$, Oecologia, (2008), doi:10.1007/s00442-012-2263-6, 2012.

Widlowski, J.-L., Pinty, B., Clerici, M., Dai, Y., De Kauwe, M., De Ridder, K., Kallel, A., Kobayashi, H., Lavergne, T., Ni-Meister, W., Olchev, A., Quaife, T., Wang, S., Yang, W., Yang, Y., and Yuan, H.: RAMI4PILPS: An intercomparison of formulations for the partitioning of solar radiation in land surface models, J. Geophys. Res., 116, doi:10.1029/2010JG001511, 2011.

Zeidel, B.: Self-Thinning and Stand Density, Forest Sci., 37, $517-$ $523,1991$. 


\section{Appendix A}

\section{Validation data}

Data on the observed forest properties and top-of-the-canopy albedo for two pine stands and two beech stands were taken from the Infrastructure for Measurements of the European Carbon Cycle (IMECC) database (accessed online at 30 April 2013: http://fluxnet.ornl.gov/site_list/Network/32). Similar data for the oak stand were provided by the Tartu Observatory (Kuusk et al., 2009, 2013).

One pine stand was located at Järvselja in Estonia (coded EE-Jär; $58.31^{\circ} \mathrm{N}, 27.30^{\circ} \mathrm{E}$ ). The stand of Scots pine (Pinus sylvestris L.) had a height of about $15 \mathrm{~m}$, an age of 125 years (in 2013) and a stand density of 1122 trees per hectare. The other pine stand (also Pinus sylvestris L.) was at Loobos in the Netherlands (coded NL-Loo; $52.17^{\circ} \mathrm{N}, 5.74^{\circ} \mathrm{E}$ ). It had a height of $15.6 \mathrm{~m}$, an age (in 2013) of 106 years and a density of about 404 trees per hectare.

One beech forest (Fagus sylvatica L.) was located at Hainich in Germany (coded DE-Hai; $51.08^{\circ} \mathrm{N}, 10.45^{\circ} \mathrm{E}$ ). This site has been totally unmanaged since 1997 . Before being classified as a reserve the forest was occasionally logged for timber over a period of about 30 years. As a consequence the forest has moved towards a late successional forest with trees aged between 1 and 250 years with the tallest trees reaching $33 \mathrm{~m}$ in height. The tree density was about 334 trees per hectare; Fraxinus excelsior and Acer pseudplatanus are co-dominant. The other beech stand was located at Hesse in France (coded FR-Hes; $48.67^{\circ} \mathrm{N}, 7.07^{\circ} \mathrm{E}$ ). It was a rather young forest (48 years in 2013) and, with 2616 trees per hectare, densely populated. The dominant tree cover was $21 \mathrm{~m}$ tall with a high canopy closure.

The oak stand was situated at Fontainebleau in France (coded FR-Fon; $48.48^{\circ} \mathrm{N}, 2.78^{\circ} \mathrm{E}$ ). It consists mainly of Quercus petraea L. In 2006 the stand density was 1134 trees per hectare, of which 234 were Quercus petraea and 900 were Carpinus betulus. The average canopy height of Quercus petraea was about $27 \mathrm{~m}$, whereas the Carpinus betulus were about 10 to $20 \mathrm{~m}$ tall; stand age (in 2013) was about 150 years.

For all validation sites, stand-level albedo was observed from in situ incoming and outgoing shortwave radiometric measurements and recorded in the IMECC database, with the exception of EE-Jär. From this database years was only selected when outgoing and incoming shortwave radiation were recorded. Albedo was calculated as the ratio of downward and upward radiation as observed with two-way pyranometers (Kipp and Zonen, Delft, The Netherlands). The overall expected instrumental accuracy is in the range 4-7\% with clear sky and 1-4\% in overcast conditions (Cescatti et al., 2012). The radiation measurements cover the wavelengths from 0.21 to $2.80 \mu \mathrm{m}$.
The albedo at EE-Jär was measured as top-of-the-canopy bidirectional reflectance factor (BRF) with a UAV spectrometer (Kuusk, 2011). The measured BRF was carried out at different dates in July and August in 2012 and transformed with the help of the $6 \mathrm{~S}$ atmosphere radiation transfer model (Vermote et al., 1997) and the FRT forest reflectance model (Kuusk and Nilson, 2000) into visible and near-infrared albedo for the solar zenith angle $39.8^{\circ}$ which corresponds to the maximum solar zenith angle at midday at the Järvselja site at summer solstice.

Only EE-Jär and DE-Hai provided measured crown sizes (Table 3). For the remaining sites, species-specific allometric relationships were used to estimate the height of the crown base, the crown radius and length derived from three different data sets (Condés and Sterba, 2005; Pretzsch et al., 2002; Zeidel, 1991). For sites where the coordinates of the individual trees were absent, we assumed a uniform tree distribution. Only the simulation for EE-Jär was run exclusively with observed parameters (see Table 3) and compared with simulated albedo. For all other sites, the observed albedo was, finally, compared to the calculated albedo. However, variation in the amount and timing of cloudiness causes considerable day-to-day variation which can be smoothed out when integrated over several weeks (Hollinger et al., 2010). Therefore, integrated daily values for the whole month of June were calculated to compare to the simulated values.

Every simulation was performed for 1 ha of forest. This 1 ha was divided in 25 squares $(20 \mathrm{~m} \times 20 \mathrm{~m})$ and the albedo was simulated for each square separately. The variation between the squares was considered to be a measure of the sensitivity of albedo to the footprint for a given canopy structure. The scan line of the UAV spectrometer is about $2.5-3.0 \mathrm{~m}$ (Kuusk, 2011). The footprint of surface albedo measured by a pyranometer depends on its height above the canopy (ranging from 5 to $10 \mathrm{~m}$ ). However, for the experimental sites under study, typically $80 \%$ of the signal originates from within $300-1200 \mathrm{~m}^{2}$ (i.e. $10-20 \mathrm{~m}$ ) around the tower (Cescatti et al., 2012). To capture all possible spatial scales of observed albedo values, each site is presented as the mean albedo of June (2001-2010) by MODIS (Pinty et al., 2011a; Schaaf et al., 2002) at $\sim 1 \mathrm{~km}$ resolution. The range of MODIS observations are derived from nine pixels surrounding the tower. 